\title{
Cytochrome P450 IAI exon 7 polymorphism and susceptibility to lung cancer in the Chinese population: an updated meta-analysis and review
}

\section{Xiu-ping Wei \\ Jie $\mathrm{Hu}$}

Respiratory Department, Beijing Tiantan Hospital affiliated to Capital Medical University, Beijing, People's Republic of China
Correspondence: Xiu-ping Wei Respiratory Department, Beijing Tiantan Hospital affiliated to Capital Medical University, No 6 Tiantan West, Dongcheng District, Beijing 100050, People's Republic of China Tel/fax +86 106709684 I Email xiupingw2002@126.com
This article was published in the following Dove Press journal:

OncoTargets and Therapy

2 July 2015

Number of times this article has been viewed

Background: Although many epidemiologic studies have investigated the cytochrome P450 1A1 (CYP1A1) exon 7 gene polymorphism and its association with lung cancer (LC), definitive conclusions cannot be drawn.

Objective: To clarify the effects of CYP1A1 exon 7 polymorphism on the risk of LC, an updated meta-analysis was performed in the Chinese population.

Methods: Related studies were identified from PubMed, Springer Link, Ovid, the Chinese Wanfang Data Knowledge Service Platform, Chinese National Knowledge Infrastructure (CNKI), and the Chinese Biology Medicine (CBM) databases until October 2014. Odds ratios (ORs) with 95\% confidence intervals (CIs) were used to assess the strength of the associations.

Results: A total of 25 articles including 3,540 LC cases and 5,284 controls were included in this meta-analysis. Overall, significant association was found between CYP1A1 exon 7 polymorphism and LC risk when all studies in the Chinese population were pooled into this meta-analysis (GG versus AA: OR =1.71, 95\% CI: 1.46-2.01; GG versus AG: OR=1.41, 95\% CI: 1.21-1.64; $\mathrm{GG}+\mathrm{AG}$ versus AA: OR $=1.37,95 \% \mathrm{CI}: 1.16-1.62$; GG versus $\mathrm{AA}+\mathrm{AG}$ : OR $=1.52,95 \% \mathrm{CI}$ : 1.32-1.76). In subgroup analyses stratified by ethnicity, source of controls, and geographical locations, significantly increased risk was found in Chinese Han people, in population-based studies, in hospital-based studies, in South China, and in North China.

Conclusion: This meta-analysis provides the evidence that CYP1A1 exon 7 polymorphism may contribute to LC development in the Chinese population, and studies with a larger sample size and wider population spectrum are warranted to verify this finding.

Keywords: epidemiology, gene, lung neoplasm, CYP1A1

\section{Introduction}

Lung cancer is the most commonly diagnosed cancer as well as the leading cause of cancer death in males globally, with 1.6 million newly confirmed cases and 1.4 million deaths from lung cancer annually. ${ }^{1}$ In the last decade, the incidence and mortality rates of lung cancer in the People's Republic of China have increased significantly and constantly. ${ }^{1}$ It was estimated that 605,946 lung cancer cases were diagnosed in 2010 in the People's Republic of China, with a crude incidence rate of 46.08/100,000, and 486,555 patients died from lung cancer, with a crude mortality rate of $37.00 / 100,000 .^{2}$ Although risk of lung cancer has been conclusively associated with tobacco smoking, ${ }^{3}$ fewer than $20 \%$ of smokers develop the disease, indicating that genetic variations and other environmental factors may play important roles in the development of lung cancer. ${ }^{4,5}$ In recent years, the impact of inherited polymorphisms in the cytochrome P450 1A1 (CYP1A1) gene on susceptibility to lung cancer has received particular interest since this enzyme plays an essential role in the metabolic activation of major classes of tobacco procarcinogen 
such as aromatic amines and polycyclic aromatic hydrocarbons. The CYP1A1 exon 7 polymorphism, resulting in the substitution of isoleucine with valine (Ile462Val) (National Center for Biotechnology Information single-nucleotide polymorphism identifier rs1048943; adenine [A] to guanine [G] substitution at nucleotide 2455 [A2455G]), is one of the most extensively studied genes in lung cancer susceptibility. An association between CYP1A1 exon 7 polymorphism and lung cancer was first reported by Nakachi et al in 1993 among the Japanese population, ${ }^{6}$ after which many studies analyzed the influence of CYP1A1 exon 7 polymorphism on lung cancer risk; no clear consensus, however, was reached. Metaanalyses of studies on the gene in other ethnic groups have been reported elsewhere and produced conflicting results. ${ }^{7-12}$ In order to lessen the impact of different genetic backgrounds, we performed this updated meta-analysis to assess the relationship of CYP1A1 exon 7 polymorphism with risk of lung cancer in the Chinese population.

\section{Materials and methods}

\section{Search strategy and selection criteria}

We systematically searched the PubMed, Springer Link, Ovid, Chinese Wanfang Data Knowledge Service Platform, Chinese National Knowledge Infrastructure (CNKI), and Chinese Biology Medicine (CBM) databases for studies published before October 10, 2014, using the following MeSH terms: ("Lung Neoplasms" [MeSH] or "lung cancer" or "lung tumor" or "lung carcinoma" or "carcinoma of lung") and ("cytochrome P450 1A1" or "CYP1A1") and ("China" or "Chinese" or "Taiwan"). The search was performed without any restrictions on language and focused on studies conducted in humans. Additional studies were identified by handsearching references in original research articles and review articles. Studies were selected according to the following criteria: 1) case-control study or cohort study studying on association between the CYP1A1 exon 7 polymorphism and lung cancer susceptibility; 2) all patients with the diagnosis of lung cancer confirmed by pathological or histological examination; 3) sufficient published data about sample size, odds ratio (OR), and their 95\% confidence interval (CI); 4) all participants were Chinese; and 5) in the case of duplication with multiple articles publishing data on the same population, the most complete dataset was included. Review papers, letters, case reports, or editorial articles were excluded.

\section{Data extraction}

Information was carefully extracted from all eligible publications independently by the two authors according to the inclusion criteria. Disagreements were resolved through a discussion between the two authors. The title and abstract of all potentially relevant articles were screened to determine their relevance. Full articles were also scrutinized if the title and abstract were ambiguous. The following data were collected from each study: first author's surname, year of publication, geographical location, ethnicity of subjects, source of controls, total numbers of cases and controls, genotype frequencies, and Hardy-Weinberg equilibrium test. Ethnicities were categorized as Han and other ethnic Chinese. We did not define any minimum number of patients to include a study in our meta-analysis. For articles including different ethnicities or areas, data were extracted separately.

\section{Statistical analysis}

The ORs with 95\% CIs were used to determine the strength of association between the CYP1A1 exon 7 polymorphisms and lung cancer risk. The pooled ORs were performed for allele model ( $G$ versus $A)$, dominant model $(\mathrm{GG}+$ $A G$ versus AA), recessive model ( $G G$ versus $A G+A A)$, heterozygous model (GG versus $A G$ ), and homozygous model (GG versus AA), respectively. The distributions of genotypes in controls were tested by Hardy-Weinberg equilibrium using the $\chi^{2}$ test. Heterogeneity assumptions were assessed by $\chi^{2}$-based $Q$-test. A $P$-value greater than 0.10 for the $Q$-test indicated a lack of heterogeneity among the studies. Thus, the pooled OR estimate of each study was calculated using either the fixed-effects model (the Mantel-Haenszel method) or the random-effects model (the DerSimonian and Laird method). The significance of the pooled OR was determined by the $z$-test. Sensitivity analysis was conducted to verify stability of the meta-analysis using both models (the fixed-effects and random-effects). Potential publication biases were estimated by funnel plot, in which the standard error of $\log$ OR of each study was plotted against its log OR. An asymmetrical plot suggests a publication bias. Funnel plot asymmetry was assessed by Egger's linear regression test, a linear regression approach that measures the funnel plot asymmetry on a natural logarithm scale of the OR. The significance of the intercept was determined by $t$-test, as suggested by $\operatorname{Egger}^{13}(P<0.05$ was considered a statistically significant publication bias). In addition, subgroup analysis stratified by ethnicity, source of controls, and geographical locations was also performed. All the statistical analyses were performed using the STATA statistical package (version 10; StataCorp LP, College Station, TX, USA). 


\section{Results}

\section{Eligible studies}

According to the inclusion criteria, 25 case-control studies ${ }^{14-38}$ were included and 163 articles were excluded. The publication year of included studies ranged from 1998 to 2014. A flowchart of the study selection process is shown in Figure 1. In total, 3,540 lung cancer cases and 5,284 controls were involved in this meta-analysis, which evaluated the relationship between CYP1A1 exon 7 polymorphism and lung cancer risk. The source of controls was mainly based on a healthy population. Fifteen of these studies were written in Chinese, and ten studies were in English. The characteristics of the included studies are summarized in Table 1.

\section{Quantitative synthesis}

Table 2 lists the primary results. Overall, a significantly elevated risk of lung cancer was associated with all variants of CYP1A1 exon 7 ( $G$ versus A: OR =1.30, 95\% CI: 1.17-1.45; GG versus AA: OR =1.71, 95\% CI: 1.46-2.01; GG versus AG: $\mathrm{OR}=1.41,95 \% \mathrm{CI}: 1.21-1.64 ; \mathrm{GG}+\mathrm{AG}$ versus AA: $\mathrm{OR}=1.37,95 \% \mathrm{CI}: 1.16-1.62$; GG versus $\mathrm{AA}+\mathrm{AG}$ : $\mathrm{OR}=1.52,95 \% \mathrm{CI}: 1.32-1.76$ ) (Figure 2). However, there was significant heterogeneity between some models. Hence, we then performed subgroup analysis by geographical locations, ethnicity, and source of controls. In the stratified analysis by geographical locations, significantly increased risk was found both in North China ( $\mathrm{G}$ versus A: OR $=1.28,95 \%$
CI: 1.13-1.46; GG versus AA: OR=1.60, 95\% CI: 1.33-1.91; GG versus $A G$ : $O R=1.31,95 \% \mathrm{CI}: 1.10-1.55 ; \mathrm{GG}+\mathrm{AG}$ versus $\mathrm{AA}$ : $\mathrm{OR}=1.41,95 \% \mathrm{CI}: 1.15-1.73$; GG versus $\mathrm{AA}+\mathrm{AG}: \mathrm{OR}=1.41,95 \% \mathrm{CI}: 1.20-1.65)$ and South China (G versus A: OR =1.39, 95\% CI: 1.10-1.76; GG versus AA: $\mathrm{OR}=2.13,95 \% \mathrm{CI}: 1.51-3.01$; GG versus $\mathrm{AG}$ : $\mathrm{OR}=1.80$, 95\% CI: 1.26-2.58; GG versus AA + AG: OR=2.01, 95\% CI: 1.44-2.81). In the stratified analysis by source of controls, significantly increased risk was found both in the population-based studies (G versus A: OR=1.32, 95\% CI: 1.15-1.50; GG versus AA: $\mathrm{OR}=1.77,95 \%$ CI: $1.36-2.31$; GG versus $\mathrm{AG}: \mathrm{OR}=1.38$, 95\% CI: 1.15-1.66; GG + AG versus AA: OR $=1.40,95 \%$ CI: $1.15-1.71$; GG versus $1 \mathrm{G}: \mathrm{OR}=1.49,95 \% \mathrm{CI}: 1.25-1.77$ ) and hospital-based studies ( $\mathrm{G}$ versus $\mathrm{A}$ : $\mathrm{OR}=1.29,95 \% \mathrm{CI}$ : 1.13-1.47; GG versus AA: OR =2.05, 95\% CI: 1.50-2.79; GG versus $A G: O R=1.44,95 \% \mathrm{CI}: 1.10-1.88 ; \mathrm{GG}+\mathrm{AG}$ versus AA: $\mathrm{OR}=1.39,95 \% \mathrm{CI}: 1.13-1.72$; GG versus AA + AG: $\mathrm{OR}=1.59,95 \% \mathrm{CI}: 1.23-2.06)$. In the subgroup analysis by ethnicity, significantly increased association was found in Chinese Han people (GG versus AA: OR $=1.59$, 95\% CI: 1.11-2.30; GG versus AG: $\mathrm{OR}=1.38,95 \% \mathrm{CI}: 1.12-1.68$; GG versus $\mathrm{AA}+\mathrm{AG}: \mathrm{OR}=1.40,95 \% \mathrm{CI}: 1.16-1.70)$.

\section{Sensitivity analysis and bias diagnosis}

In order to compare the difference and evaluate the sensitivity of the meta-analysis, we used both models (fixed-effects and random-effects) to evaluate the stability of the meta-analysis.

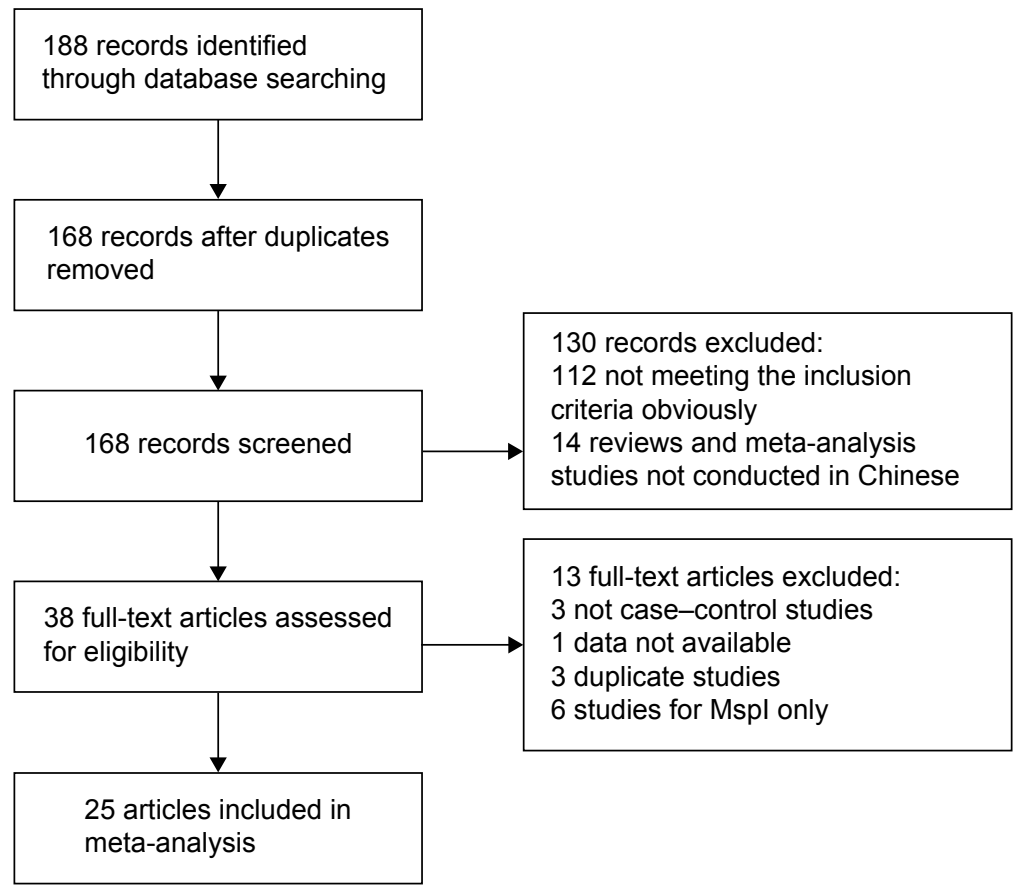

Figure I Flow diagram of the literature search. 
Table I Characteristics of studies included in the meta-analysis

\begin{tabular}{|c|c|c|c|c|c|c|c|c|c|c|c|c|c|}
\hline \multirow[t]{2}{*}{ Study } & \multirow{2}{*}{$\begin{array}{l}\text { Source of } \\
\text { controls }\end{array}$} & \multirow[t]{2}{*}{ Area } & \multirow[t]{2}{*}{ Ethnicity } & \multirow{2}{*}{$\begin{array}{l}\text { Number } \\
\text { of cases }\end{array}$} & \multirow{2}{*}{$\begin{array}{l}\text { Number } \\
\text { of controls }\end{array}$} & \multicolumn{3}{|c|}{ Case } & \multicolumn{3}{|c|}{ Control } & \multicolumn{2}{|l|}{ HWE } \\
\hline & & & & & & $\overline{A A}$ & AG & $\mathbf{G G}$ & $\overline{A A}$ & AG & GG & $\overline{\chi^{2}}$ & $P$-value \\
\hline Hu and Zhang ${ }^{14}$ & $\mathrm{~PB}+\mathrm{HB}$ & Guangdong & Han & 59 & 132 & 19 & 33 & 7 & 21 & 102 & 9 & 41.12 & 0.000 \\
\hline Qu et $\mathrm{al}^{15}$ & $\mathrm{~PB}$ & Shanghai & Not stated & 100 & 95 & 56 & 36 & 8 & 56 & 35 & 4 & 0.26 & 0.612 \\
\hline Qu et $\mathrm{al}^{15}$ & PB & Heilongjiang & Not stated & 80 & 87 & 42 & 36 & 2 & 52 & 32 & 3 & 0.52 & 0.470 \\
\hline Chen et $\mathrm{al}^{16}$ & $\mathrm{~PB}$ & Jiangsu & Not stated & 68 & 105 & 35 & 21 & 12 & 66 & 30 & 9 & 3.78 & 0.052 \\
\hline Persson et al ${ }^{17}$ & $\mathrm{~PB}$ & Beijing & Not stated & 76 & 119 & 50 & 20 & 6 & 77 & 37 & 5 & 0.04 & 0.835 \\
\hline Song et $\mathrm{al}^{18}$ & PB & Beijing & Not stated & 150 & 391 & 53 & 90 & 7 & 200 & 178 & 13 & 12.74 & 0.000 \\
\hline London et $\mathrm{al}^{19}$ & PB & Shanghai & Not stated & 214 & 669 & 167 & 39 & 8 & 512 & 130 & 27 & 21.86 & 0.000 \\
\hline Song et $\mathrm{a}^{20}$ & $\mathrm{~PB}$ & Beijing & Not stated & 217 & 404 & 78 & 130 & 9 & 210 & 181 & 13 & 12.45 & 0.000 \\
\hline Zhang et $\mathrm{al}^{21}$ & $\mathrm{HB}$ & Jiangsu & Not stated & 40 & 30 & 17 & 13 & 10 & 18 & 10 & 2 & 0.14 & 0.708 \\
\hline Chen et $\mathrm{a}^{22}$ & $\mathrm{~PB}$ & Jiangsu & Not stated & 106 & 106 & 58 & 38 & 10 & 70 & 33 & 3 & 0.14 & 0.704 \\
\hline Zhou et $\mathrm{a}^{23}$ & $\mathrm{HB}$ & Hubei & Not stated & 92 & 98 & 15 & 66 & II & 27 & 65 & 6 & 14.93 & 0.000 \\
\hline Zhang et $\mathrm{a}^{24}$ & $\mathrm{HB}$ & Jiangsu & Not stated & 65 & 60 & 24 & 29 & 12 & 32 & 23 & 5 & 0.09 & 0.765 \\
\hline Dong et $\mathrm{a}^{25}$ & $\mathrm{HB}$ & Sichuan & Not stated & 82 & 91 & 28 & 36 & 18 & 49 & 32 & 10 & 1.74 & 0.187 \\
\hline Yang et $\mathrm{a}^{26}$ & PB & Liaoning & Not stated & 197 & 144 & 90 & 96 & 11 & 98 & 39 & 7 & 0.82 & 0.239 \\
\hline $\mathrm{Ng}$ et $\mathrm{al}^{27}$ & $\mathrm{HB}$ & Singapore & Not stated & 126 & $16 \mid$ & 74 & 39 & 13 & 91 & 63 & 7 & 0.91 & 0.339 \\
\hline Liu et $\mathrm{a}^{28}$ & $\mathrm{~PB}$ & Shandong & Han & 110 & 125 & 18 & 80 & 12 & 35 & 83 & 7 & 19.820 & 0.000 \\
\hline Song et $\mathrm{al}^{29}$ & PB & Shandong & Han & 125 & 125 & 20 & 90 & 15 & 36 & 80 & 9 & 14.68 & 0.000 \\
\hline Zhou et a $\left.\right|^{30}$ & $\mathrm{~PB}$ & Henan & Not stated & 209 & 208 & 39 & 135 & 35 & 55 & 128 & 25 & 13.73 & 0.000 \\
\hline Wang et $\mathrm{al}^{31}$ & $\mathrm{~PB}$ & Liaoning & Han & 72 & 90 & 37 & 9 & 26 & 54 & 25 & 11 & 7.06 & 0.008 \\
\hline Bai et $\mathrm{a}^{32}$ & $\mathrm{HB}$ & Inner Mongolia & Han & 106 & 250 & 25 & 66 & 15 & 54 & 172 & 24 & 39.22 & 0.000 \\
\hline Wang et $\mathrm{al}^{33}$ & $\mathrm{~PB}$ & Henan & Han & 209 & 256 & 95 & 66 & 48 & 148 & 70 & 38 & 27.76 & 0.000 \\
\hline Lv et $\mathrm{al}^{34}$ & $\mathrm{HB}$ & Inner Mongolia & Han & 116 & 216 & 17 & 75 & 24 & 44 & 133 & 39 & 11.64 & 0.001 \\
\hline Liu et $\mathrm{a}^{35}$ & $\mathrm{HB}$ & Inner Mongolia & Han & 174 & 324 & 26 & 112 & 36 & 66 & 200 & 58 & 17.94 & 0.000 \\
\hline He et $\mathrm{al}^{36}$ & $\mathrm{~PB}$ & Hebei & Han & 275 & 406 & $|4|$ & 103 & 31 & 165 & 183 & 58 & 0.40 & 0.529 \\
\hline Jiang et $\mathrm{al}^{37}$ & PB & Inner Mongolia & Mongolian & 142 & 190 & 18 & 101 & 23 & 28 & 136 & 26 & 35.42 & 0.000 \\
\hline Jiang et $\mathrm{al}^{37}$ & $\mathrm{~PB}$ & Inner Mongolia & Han & 180 & 266 & 42 & 112 & 26 & 57 & 183 & 26 & 41.48 & 0.000 \\
\hline Yang et $\mathrm{a}^{38}$ & PB & Hebei & Not stated & 150 & 136 & 52 & 75 & 23 & 61 & 65 & 10 & 1.72 & 0.190 \\
\hline
\end{tabular}

Abbreviations: $\mathrm{HB}$, hospital-based; HWE, Hardy-Weinberg equilibrium; $\mathrm{PB}$, population-based.

None of the results were materially altered (Table 2). Hence, the results of the sensitivity analysis suggest that the data in this meta-analysis are relatively stable and credible. Begg's funnel plot and Egger's test were performed to assess publication bias. The shape of the funnel plots did not reveal obvious asymmetry (Figure 3A). Subsequently, the Egger's test was used to provide statistical evidence of funnel plot symmetry. The Egger's test indicated that there was no obvious publication bias under the allele model in overall analysis (Figure 3B) $(t=2.09, P=0.058)$.

\section{Discussion}

Cytochrome P450 genes are large families of endoplasmic and cytosolic enzymes that catalyze the activation and detoxification, respectively, of reactive electrophilic compounds, including many environmental carcinogens (eg, benzo[a]pyrene). CYP1A1 is a phase I enzyme that regulates the metabolic activation of major classes of tobacco procarcinogens, such as aromatic amines and polycyclic aromatic hydrocarbons. ${ }^{39}$ Thus, CYP1A1 may affect the metabolism of environmental carcinogens and alter the susceptibility to lung cancer. Although many studies have analyzed the CYP1A1 exon 7 polymorphism and its association with lung cancer, definitive conclusions cannot be drawn. Therefore, we performed the current meta-analysis to estimate the relationship between CYP1A1 exon 7 polymorphism and susceptibility to lung cancer among the Chinese population only, in order to lessen the impact of different genetic backgrounds. The meta-analysis involved 25 articles including 3,540 lung cancer cases and 5,284 controls. The results showed that the variant genotypes of the CYP1A1 exon 7 polymorphism were significantly associated with lung cancer risk in the Chinese population. Our results were consistent with a previously published meta-analysis in Chinese populations, ${ }^{40}$ which found that, compared with the wild-type homozygous genotype (AA), lung cancer risk for the combined variant genotypes ( $\mathrm{GG}$ and $\mathrm{AG}$ ) was 1.61fold (95\% CI: 1.24-2.08) $(Z=3.62, P<0.001)$. However, this previously published meta-analysis did not search some other databases in the People's Republic of China (Wanfang Data Knowledge Service Platform and CBM), and included a smaller number of studies than ours did. 
Table 2 Main results in the total and subgroup analysis

\begin{tabular}{|c|c|c|c|c|c|c|}
\hline \multirow[t]{2}{*}{ Analysis model } & \multirow{2}{*}{$\begin{array}{l}\text { Study } \\
\text { groups }\end{array}$} & \multirow[t]{2}{*}{$\mathbf{n}$} & \multirow{2}{*}{$\begin{array}{l}\text { Random-effects } \\
\text { model } \\
\text { OR }(95 \% \mathrm{Cl})\end{array}$} & \multirow{2}{*}{$\begin{array}{l}\text { Fixed-effects } \\
\text { model } \\
\text { OR }(95 \% \mathrm{CI})\end{array}$} & \multicolumn{2}{|c|}{ Heterogeneity } \\
\hline & & & & & $\chi^{2}$ & $P$-value \\
\hline \multirow[t]{6}{*}{$G$ versus $A$} & Total analysis & 27 & I.30 (I.I7-I.45) & $1.26(1.18-1.35)$ & 61.48 & 0.000 \\
\hline & PB & 18 & $1.32(1.15-1.50)$ & $1.27(1.17-1.37)$ & 46.80 & 0.000 \\
\hline & $\mathrm{HB}$ & 8 & $1.32(1.12-1.56)$ & $1.29(1.13-1.47)$ & 10.36 & 0.169 \\
\hline & Chinese Han & 10 & I.I8 (0.98-I.42) & $1.13(1.03-1.25)$ & 31.77 & 0.000 \\
\hline & South China & 9 & $1.39(1.10-1.76)$ & I.32 (I.I4-I.53) & 18.47 & 0.018 \\
\hline & North China & 17 & $1.28(1.13-1.46)$ & $1.25(1.16-1.35)$ & 42.07 & 0.000 \\
\hline \multirow[t]{6}{*}{ GG versus $A A$} & Total analysis & 27 & I.8I (1.48-2.22) & I.7I (I.46-2.0I) & 37.36 & 0.069 \\
\hline & PB & 18 & $\mathrm{I} .77(\mathrm{I} .36-2.3 \mathrm{I})$ & $1.63(1.35-1.97)$ & 29.23 & 0.032 \\
\hline & $\mathrm{HB}$ & 8 & $2.02(1.48-2.77)$ & 2.05 (1.50-2.79) & 5.54 & 0.595 \\
\hline & Chinese Han & 10 & $1.59(1.11-2.30)$ & $1.46(1.17-1.81)$ & 22.29 & 0.008 \\
\hline & South China & 9 & $2.18(1.43-3.33)$ & $2.13(1.51-3.01)$ & 10.47 & 0.233 \\
\hline & North China & 17 & $1.69(1.33-2.15)$ & $1.60(1.33-1.91)$ & 24.78 & 0.074 \\
\hline \multirow[t]{6}{*}{ GG versus $A G$} & Total analysis & 27 & $\mathrm{I} .40(\mathrm{I} .20-\mathrm{I} .64)$ & I.4I (I.2I-I.64) & 26.21 & 0.452 \\
\hline & $\mathrm{PB}$ & 18 & I.38 (I.I3-I.70) & $1.38(1.15-1.66)$ & 19.24 & 0.315 \\
\hline & $\mathrm{HB}$ & 8 & 1.43 (I.09-I.87) & $1.44(1.10-1.88)$ & 5.90 & 0.552 \\
\hline & Chinese Han & 10 & I.45 (I.I I-I.89) & $1.38(1.12-1.68)$ & 14.14 & 0.118 \\
\hline & South China & 9 & I.79 (I.24-2.58) & $1.80(1.26-2.58)$ & 3.43 & 0.905 \\
\hline & North China & 17 & I.3। (I.09-I.58) & I.3I (I.10-I.55) & 18.08 & 0.319 \\
\hline \multirow[t]{6}{*}{$G G+A G$ versus $A A$} & Total analysis & 27 & $1.37(1.16-1.62)$ & I.33 (I.2I-I.47) & 73.01 & 0.000 \\
\hline & $\mathrm{PB}$ & 18 & $\mathrm{I} .40(\mathrm{I} . \mathrm{I5}-\mathrm{I} .7 \mathrm{I})$ & $1.35(1.22-\mid .5 \mathrm{I})$ & 51.52 & 0.000 \\
\hline & $\mathrm{HB}$ & 8 & 1.43 (I.I0-I.87) & $1.39(1.13-1.72)$ & 10.40 & 0.167 \\
\hline & Chinese Han & 10 & I.I 6 (0.84-I.59) & I. 10 (0.94-I.27) & 35.24 & 0.000 \\
\hline & South China & 9 & I.35 (0.97-I.89) & $1.28(1.05-1.55)$ & 21.40 & 0.006 \\
\hline & North China & 17 & $1.4 \mid(1.15-1.73)$ & I.38 (I.24-I.55) & 48.58 & 0.000 \\
\hline \multirow[t]{6}{*}{$G G$ versus $A A+A G$} & Total analysis & 27 & $\mathrm{I} .54(\mathrm{I} .32-\mathrm{I} .80)$ & $1.52(1.32-1.76)$ & 28.79 & 0.321 \\
\hline & PB & 18 & I.53 (I.24-I.88) & 1.49 (I.25-I.77) & 21.82 & 0.192 \\
\hline & $\mathrm{HB}$ & 8 & $\mathrm{I} .57$ (I.20-2.03) & $1.59(1.23-2.06)$ & 6.73 & 0.458 \\
\hline & Chinese Han & 10 & $1.49(1.13-1.95)$ & $1.40(1.16-1.70)$ & 16.29 & 0.061 \\
\hline & South China & 9 & $1.99(1.4 \mid-2.80)$ & $2.01(1.44-2.81)$ & 5.72 & 0.678 \\
\hline & North China & 17 & 1.42 (I.19-I.7I) & I.4I (I.20-I.65) & 18.74 & 0.283 \\
\hline
\end{tabular}

Notes: South China including Guangdong, Shanghai, Jiangsu, Hubei, and Sichuan; North China including Heilongjiang, Beijing, Liaoning, Inner Mongolia, Hebei, Shandong, and Henan.

Abbreviations: $\mathrm{Cl}$, confidence interval; $\mathrm{HB}$, hospital-based; OR, odds ratio; $\mathrm{PB}$, population-based.

The effects of genetic polymorphisms on cancer risk seem to be affected by ethnic background. Several studies have shown that the CYP1A1 exon 7 polymorphism is associated with an increased lung cancer risk in the Asian population. ${ }^{7-9}$ However, previous research, including some pooled analyses, suggest that there is not an established association between this polymorphism and increased lung cancer risk in Caucasian populations. ${ }^{10,41}$ Therefore, we performed the subgroup analyses by ethnicity, source of controls, and geographical locations. The results revealed that significant association with susceptibility to the development of lung cancer was found in Chinese Han people, in population-based studies, in hospitalbased studies, in South China, and in North China. The ethnic differences might be ascribed to genetic backgrounds and the gene-environment interactions in the etiology. In addition, the CYP1A1 exon 7 variant genotype has a high prevalence among Asians compared with Caucasians and African-Americans.
The pathways of carcinogen metabolism are complex, mediated by the activity of multiple enzymes. The effect of any single gene might have a more limited impact than has so far been anticipated. Lung cancer has some known major environmental determinants other than tobacco smoke, and large studies with detailed exposure information are needed to evaluate reliably any moderate genetic effects. Otherwise, some limitations should be acknowledged. First, we did not perform subgroup analysis on smoking status, because of the lack of sufficient data. Second, our results were based on unadjusted estimates. More precise analyses can be conducted if individual data were available, which would allow for the adjustment by other covariates including age, sex, location, race, and other factors. Final, heterogeneity is a potential problem when interpreting the results of metaanalysis. As significant between-study heterogeneity existed in a few comparisons, the results from meta-analysis should 


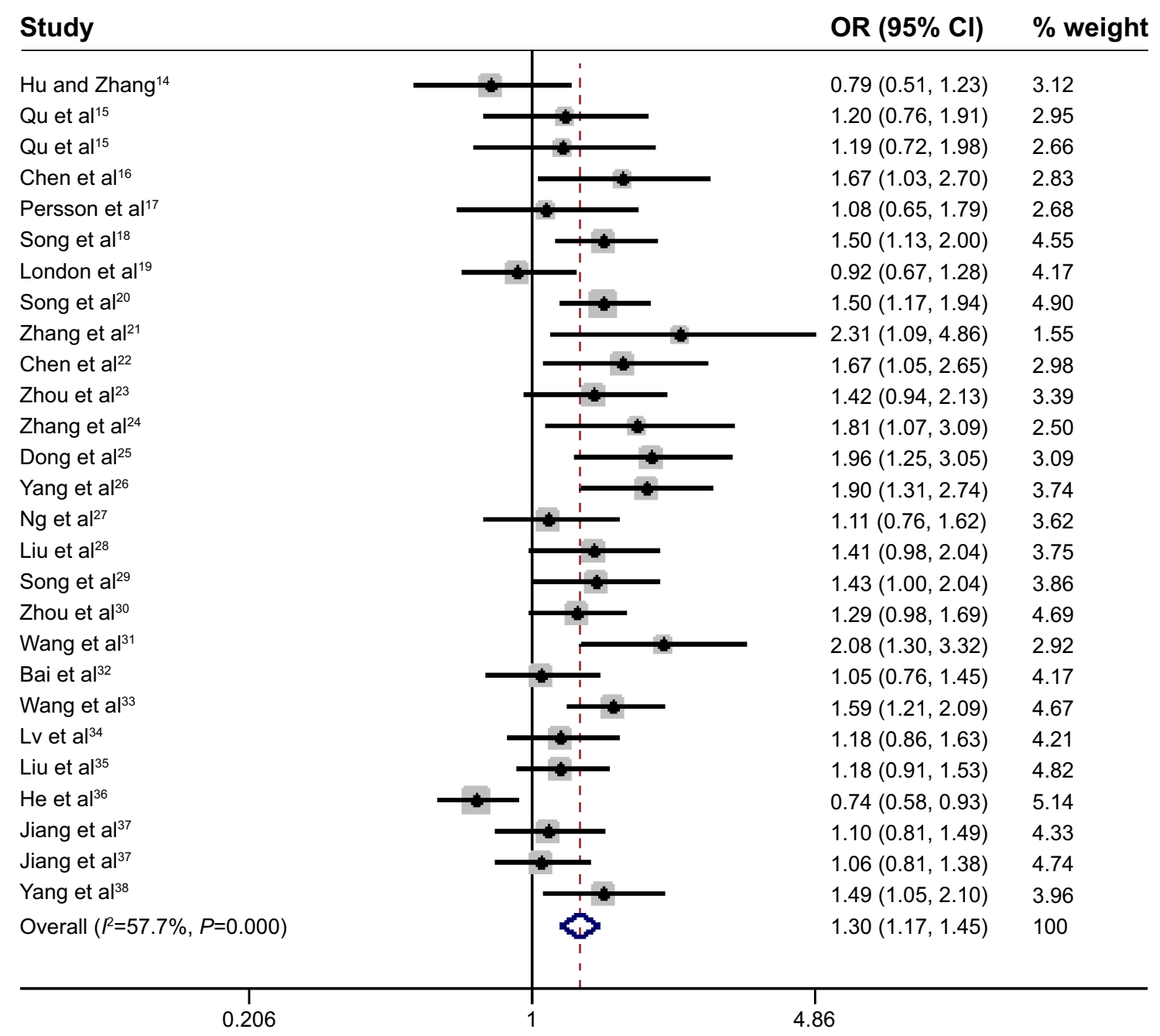

Figure 2 Forest plot (random-effects model) of lung cancer risk associated with CYPIAI Mspl polymorphism using the allele genetic model. Note: Weights are from random-effects analysis.

Abbreviations: $\mathrm{Cl}$, confidence interval; OR, odds ratio.

A $\quad$ Funnel plot with pseudo $95 \%$
confidence limits

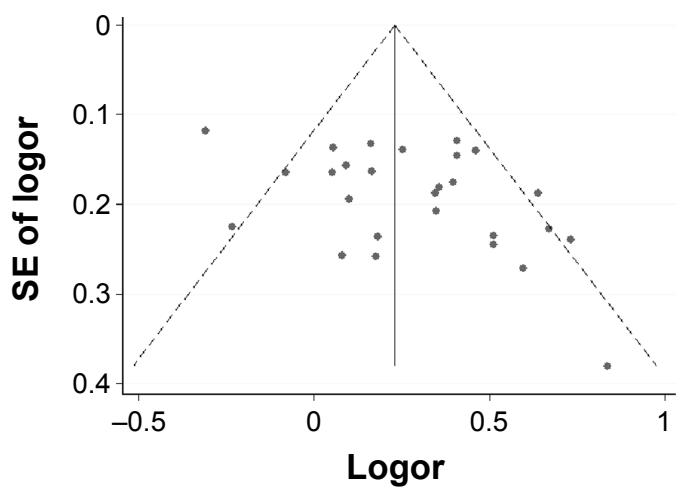

B Egger's publication bias plot

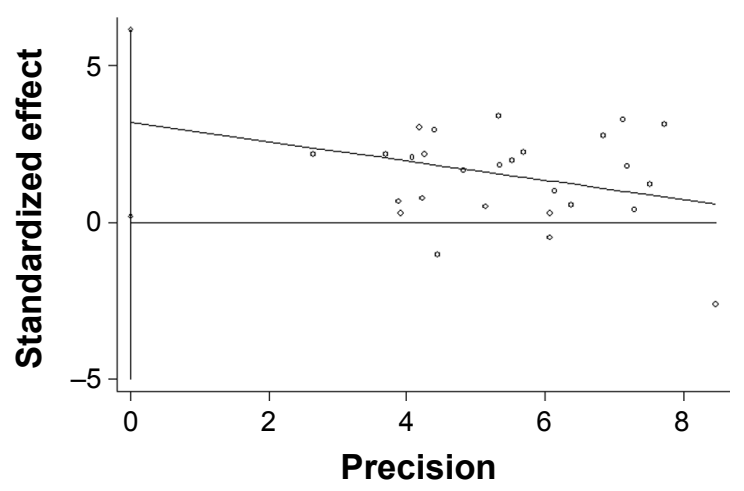

Figure 3 Publication bias assessment of CYPIAI Mspl polymorphism and lung cancer risk under the allele genetic model. Notes: (A) Begg's funnel plot. (B) Egger's test.

Abbreviation: SE, standard error. 
be interpreted with an appropriate degree of caution. In spite of these limitations, our meta-analysis still had some advantages. Most of all, we obeyed the inclusion and exclusion criteria strictly to reduce selection bias. Besides, our inclusion of non-English-language reports was important in minimizing a major potential threat to the validity of any meta-analysis publication bias and the related threat of a language bias. Last but not least, there was no evidence of publication bias in this meta-analysis and the sensitivity analysis confirmed the reliability and stability of the results. Therefore, the 25 studies would appear to be comparable in all respects relevant to our meta-analysis.

\section{Conclusion}

Our meta-analysis supports that CYP1A1 exon 7 polymorphism might contribute to individual susceptibility to lung cancer in Chinese. Concerning lung cancer with multifactorial etiology, to further evaluate gene-gene and gene-environment interactions on CYP1A1 exon 7 and lung cancer, larger studies in selected populations with different environmental backgrounds or other risk factors are required. Such studies may eventually lead to a better, comprehensive understanding of the association between the CYP1A1 exon 7 and lung cancer risk.

\section{Disclosure}

The authors report no conflicts of interest in this work.

\section{References}

1. Jemal A, Bray F, Center MM, Ferlay J, Ward E, Forman D. Global cancer statistics. CA Cancer J Clin. 2011;61(2):69-90.

2. Zheng R, Zeng $\mathrm{H}$, Zhang $\mathrm{S}$, et al. Lung cancer incidence and mortality in China, 2010. Thorac Cancer. 2014;5(4):330-336.

3. Vineis P, Alavanja M, Buffler P, et al. Tobacco and cancer: recent epidemiological evidence. J Natl Cancer Inst. 2004;96(2): 99-106.

4. Osann KE. Epidemiology of lung cancer. Curr Opin Pulm Med. 1998; 4(4):198-204

5. Hecht SS. Cigarette smoking and lung cancer: chemical mechanisms and approaches to prevention. Lancet Oncol. 2002;3(8): 461-469.

6. Nakachi K, Imai K, Hayashi S, Kawajiri K. Polymorphisms of the CYP1A1 and glutathione S-transferase genes associated with susceptibility to lung cancer in relation to cigarette dose in a Japanese population. Cancer Res. 1993;53(13):2994-2999.

7. Wu B, Liu K, Huang H, et al. MspI and Ile462Val polymorphisms in CYP1A1 and overall cancer risk: a meta-analysis. PLoS One. 2013; 8(12):e85166.

8. Xu CH, Wang Q, Qian Q, Zhan P, Yu LK. CYP1A1 exon7 polymorphism is associated with lung cancer risk among the female population and among smokers: a meta-analysis. Tumour Biol. 2013;34(6):3901-3911.

9. Zhan P, Wang Q, Qian Q, Wei SZ, Yu LK. CYP1A1 MspI and exon7 gene polymorphisms and lung cancer risk: an updated meta-analysis and review. J Exp Clin Cancer Res. 2011;30:99.
10. Chen Z, Li Z, Niu X, et al. The effect of CYP1A1 polymorphisms on the risk of lung cancer: a global meta-analysis based on 71 case-control studies. Mutagenesis. 2011;26(3):437-446.

11. Le Marchand L, Guo C, Benhamou S, et al. Pooled analysis of the CYP1A1 exon 7 polymorphism and lung cancer (United States). Cancer Causes Control. 2003;14(4):339-346.

12. Houlston RS. CYP1A1 polymorphisms and lung cancer risk: a metaanalysis. Pharmacogenetics. 2000;10(2):105-114.

13. Egger M, Davey Smith G, Schneider M, Minder C. Bias in metaanalysis detected by a simple, graphical test. BMJ. 1997;315(7109): 629-634.

14. Hu Y, Zhang Q. [Genetic polymorphisms of CYP1A1 and susceptibility of lung cancer]. Zhonghua Yi Xue Yi Chuan Xue Za Zhi. 1999; 16(1):26-28. Chinese.

15. Qu YH, Shi YB, Zhang LJ, et al. The genotypes of cytochrome P450 1A1 and GST M1 in non-smoking female lung cancer. Tumor (Shanghai). 1998;18(2):80-82. Chinese.

16. Chen SQ, Xu L, Ma JG, Wu JZ, Xue KX. Identification of genetic polymorphism of CYP1A1 and GSTM1 in lung cancer patients by using allele-specific PCR and multiplex differential PCR. Carcinogenesis, Teratogenesis \& Mutagenesis. 1999;11(3):119-122. Chinese.

17. Persson I, Johansson I, Lou YC, et al. Genetic polymorphism of xenobiotic metabolizing enzymes among Chinese lung cancer patients. Int J Cancer. 1999;81(3):325-329.

18. Song N, Tan W, Tang H, Lin D. Impact of cytochrome P450 1A1 gene mutations on the risk of development of lung cancer in a Chinese population. Ai Zheng. 1999;18(5):495-498. Chinese.

19. London SJ, Yuan JM, Coetzee GA, Gao YT, Ross RK, Yu MC. CYP1A1 I462V genetic polymorphism and lung cancer risk in a cohort of men in Shanghai, China. Cancer Epidemiol Biomarkers Prev. 2000;9(9): 987-991.

20. Song N, Tan W, Xing D, Lin D. CYP 1A1 polymorphism and risk of lung cancer in relation to tobacco smoking: a case-control study in China. Carcinogenesis. 2001;22(1):11-16.

21. Zhang LZ, Wang X, Shi YX. Susceptibility to lung cancer is associated with genetic polymorphism of cytochrome P450 (CYP1A1). Acta Academiae Medicinae Xuzhou. 2001;21(1):8-10. Chinese.

22. Chen S, Xue K, Xu L, Ma G, Wu J. Polymorphisms of the CYP1A1 and GSTM1 genes in relation to individual susceptibility to lung carcinoma in Chinese population. Mutat Res. 2001;458(1-2):41-47.

23. Zhou XW, Shi Y, Zhou YK. The relationship between CYP1A1 genetic polymorphism and susceptibility to lung cancer. J Environ Occup Med. 2002;19(6):355-357, 387. Chinese.

24. Zhang LZ, Wang X, Hao XZ, Shi YX, Liu ZH. Relationship between susceptibility to lung cancer and genetic polymorphism in CYP1A1, GSTM1. Chin J Clin Oncol. 2002;29(8):536-540. Chinese.

25. Dong C, Yang Q, Jiang B, Dong Q. [Study on the relationship between polymorphisms of CYP1A1 gene and susceptibility of lung cancer in Sichuan population]. Zhongguo Fei Ai Za Zhi. 2004;7(1):38-42. Chinese.

26. Yang XR, Wacholder S, Xu Z, et al. CYP1A1 and GSTM1 polymorphisms in relation to lung cancer risk in Chinese women. Cancer Lett. 2004;214(2):197-204.

27. Ng DP, Tan KW, Zhao B, Seow A. CYP1A1 polymorphisms and risk of lung cancer in non-smoking Chinese women: influence of environmental tobacco smoke exposure and GSTM1/T1 genetic variation. Cancer Causes Control. 2005;16(4):399-405.

28. Liu Q, Liu J, Song B, Wang ZH. Relationship between susceptibility to lung cancer and genetic polymorphism. Shandong Medical Journal. 2008;48(9):32-34. Chinese.

29. Song B, Liu J, Huang HY, et al. Effects of metabolic enzyme CYP1A1 and GSTM1 gene polymorphisms and smoking factors on the occurrence of male lung squamous cell carcinoma. Basic \& Clinical Medicine. 2010;30(11):1193-1196. Chinese. 
30. Zhou JL, Yao ZJ, Zeng ZP, et al. Case-control study for the relationship of CYP1A1 and CYP2D6 polymorphisms with the genetic susceptibility to lung cancer. Journal of Guangdong Pharmaceutical University. 2011;27(5):528-531. Chinese.

31. Wang ZZ, Wang CB, Ma YG. Association of I462V polymorphism of gene with non-small cell lung cancer. Progress of Anatomical Sciences. 2011;17(4):361-363. Chinese.

32. Bai TY, Chang FH, Wang MJ. Relationship between GSTT1 and CYP1A1 genetic polymorphisms and lung cancer susceptibility. Chinese Journal of Public Health. 2011;27(6):723-725. Chinese.

33. Wang N, Wu Y, Zhou X, Wu Y. [Association between genetic polymorphism of metabolizing enzymes and DNA repairing enzymes and the susceptibility of lung cancer in Henan population]. Wei Sheng Yan Jiu. 2012;41(2):251-256. Chinese.

34. Lv XL, Chang FH, Yin Q, Wang G. Associations of genetic polymorphisms of GSTP1 and CYP1A1 with susceptibility to lung cancer. Chinese Journal of Public Health. 2013;29(2):169-172. Chinese.

35. Liu C, Chang FH, Ma J, Wang G. Susceptibility of lung cancer and polymorphisms of CYP1A1 and GSTM3 genes. Chinese Journal of Public Health. 2013;29(2):172-175. Chinese.
36. He B, Lin J, Cao L, et al. [Association of CYP1A1 Ile462Val polymorphisms with susceptibility to small cell lung cancer]. Wei Sheng Yan Jiu. 2014;43(3):393-396, 418. Chinese.

37. Jiang XY, Chang FH, Bai TY, Lv XL, Wang MJ. Susceptibility of lung cancer with polymorphisms of CYP1A1, GSTM1, GSTM3, GSTT1 and GSTP1 genotypes in the population of Inner Mongolia region. Asian Pac J Cancer Prev. 2014;15(13):5207-5214.

38. Yang CJ, Liu F, Sun L, Liu JJ, Liu KY. Susceptibility of lung cancer with polymorphisms of CYP1A1 and smoking. Chin J Gerontology. 2014;34(2):616-618. Chinese.

39. Guengerich FP, Shimada T. Activation of procarcinogens by human cytochrome P450 enzymes. Mutat Res. 1998;400(1-2):201-213.

40. Shi X, Zhou S, Wang Z, Zhou Z, Wang Z. CYP1A1 and GSTM1 polymorphisms and lung cancer risk in Chinese populations: a metaanalysis. Lung Cancer. 2008;59(2):155-163.

41. Wang JJ, Zheng Y, Sun L, et al. CYP1A1 Ile462Val polymorphism and susceptibility to lung cancer: a meta-analysis based on 32 studies. Eur J Cancer Prev. 2011;20(6):445-452.
OncoTargets and Therapy

\section{Publish your work in this journal}

OncoTargets and Therapy is an international, peer-reviewed, open access journal focusing on the pathological basis of all cancers, potential targets for therapy and treatment protocols employed to improve the management of cancer patients. The journal also focuses on the impact of management programs and new therapeutic agents and protocols on

\section{Dovepress}

patient perspectives such as quality of life, adherence and satisfaction The manuscript management system is completely online and includes a very quick and fair peer-review system, which is all easy to use. Visit http://www.dovepress.com/testimonials.php to read real quotes from published authors. 